\title{
Examining urban land-cover characteristics and ecological regulation during the construction of Xiong'an New District, Hebei Province, China
}

\author{
KUANG Wenhui ${ }^{1}$, YANG Tianrong ${ }^{1,2}$, YAN Fengqin ${ }^{2,3}$ \\ 1. Institute of Geographic Sciences and Natural Resources Research, CAS, Beijing 100101, China; \\ 2. University of Chinese Academy of Sciences, Beijing 100049, China; \\ 3. Northeast Institute of Geography and Agroecology, CAS, Changchun 130102, China
}

\begin{abstract}
Development of Xiong'an New District (XND) is integral to the implementation of the Beijing-Tianjin-Hebei (BTH) Integration Initiative. It is intended to ease the non-capital functions of Beijing, optimize regional spatial patterns, and enhance ecosystem services and living environment in this urban agglomeration. Applying multi-stage remote sensing (RS) images, land use/cover change (LUCC) data, ecosystem services assessment data, and high-precision urban land-cover information, we reveal the regional land-cover characteristics of this new district as well as across the planned area of the entire BTH urban agglomeration. Corresponding ecological protection and management strategies are also proposed. Results indicated that built-up areas were rapidly expanding, leading to a continuous impervious surface at high density. Urban and impervious surface areas (ISAs) grew at rates 1.27 and 1.43 times higher than that in the 2000s, respectively, seriously affecting about $15 \%$ area of the sub-basins. Construction of XND mainly encompasses Xiongxian, Rongcheng, and Anxin counties, areas which predominantly comprise farmland, townships and rural settlements, water, and wetland ecosystems. The development and construction of XND should ease the non-capital functions of Beijing, as well as moderately control population and industrial growth. Thus, this development should be included within the national 'sponge city' construction pilot area in early planning stages, and reference should be made to international low-impact development modes in order to strengthen urban green infrastructural construction. Early stage planning based on the existing characteristics of the underlying surface should consider the construction of green ecological patches and ecological corridors between XND and the cities of Baoding, Beijing, and Tianjin. The proportion of impervious surfaces should not exceed $60 \%$, while that of the core area should not exceed $70 \%$. The development of XND needs to initiate the concept of 'planning a city according to water resource amount' and incorporate rainwater collection and recycling.
\end{abstract}

Keywords: Xiong'an New District; urban land use; urban impervious surface; Beijing-Tianjin-Hebei urban agglomeration; ecological protection strategies

Received: 2017-04-26 Accepted: 2017-06-21

Foundation: Key Project of Beijing Natural Science Foundation, No.8171004

Author: Kuang Wenhui, PhD and Associate Professor, specialized in Land Use/Cover Change (LUCC) and urban ecology. E-mail: kuangwh@igsnrr.ac.cn 


\section{Introduction}

It is well known that the processes of global warming and rapid urbanization are seriously affecting human well-being, urban settlements, and ecosystem services. Thus, as a result of major global research projects including the International Millennium Ecosystem Assessment, Urbanization and Global Environmental Change, and Future Earth, as well as the study of 'global change and urban ecology' and other key academic developments, upgrading urban ecosystem services and improving human well-being have become a focus for scholars around the world (Grimm et al., 2008; Pickett et al., 2014; Ouyang et al., 2016).

In concert with rapid global urbanization, Chinese cities have also expanded at an unprecedented rate, especially during the first decade of the 21 st century; the present rate of urban expansion in China is about 2.16 times higher than that of the 1990s. The conversion of natural and semi-natural ecosystems to artificial ones as the result of urbanization can seriously affect ecosystem structures, processes (e.g., water and heat), and service functions (e.g., support, supply, regulation, and cultural services), leading to the development of urban heat island and the intensification of extreme heating events (Jones et al., 2015; Kuang et al., 2015a; Lelieveld et al., 2015), environmental pollution (Leichenko, 2011), and frequent disasters due to flooding (Jha et al., 2012). In order to improve environmental adaptability to mitigate the risk of natural disasters and realize ecological sustainable development, the concepts of Ecosystem-based approaches to Adaptability (EbA) (Jones et al., 2012) and 'Resilience' (Holling, 1973) have been applied in ecology. Gunderson and Holling (2002) proposed 'panarchy' and the 'multi-scale nested adaptive cycle model' as representative of urban ecological elasticity; these concepts can be applied to provide new scientific ideas and solutions to understand the underlying evolutionary mechanisms of urban ecosystems (Meerow et al., 2016).

Since the beginning of the 21 st century, 'urban agglomerations' have become core to the concept of 'new urbanization' and economic development in China. However, the healthy and coordinated development of these areas is key to sustainable development, both nationally and globally (Lu, 2008; Guo et al., 2010; Gu, 2011). Subsequent to adoption of the 'Beijing-Tianjin-Hebei Cooperation and Development Strategy' at the meeting of the Political Bureau of the CPC Central Committee in April 2015, coordinated development of the Beijing-Tianjin-Hebei (BTH) urban agglomeration, the third largest urban agglomeration in China, became a priority at the national strategic level. Understanding how to efficiently and accurately extract surface coverage information from this urban agglomeration at different scales as well as conducting real-time dynamic monitoring to meet its application requirements is of great significance (Fang et al., 2016; Peng et al., 2016). The timely and accurate monitoring of urban surface features using remote sensing (RS) technology has also become a key topic in the study of urbanization and its eco-environmental effects. Monitoring is clearly of great significance to the scientific planning of towns, the rational distribution of industrial structures, and the improvement of urban system development strategies (Weng et al., 2009; Wu et al., 2011; Liu et al., 2012; Kuang et al., 2015b).

The CPC Central Committee and the State Council initiated the creation of Xiong'an New District (XND) on April 1st, 2017 and defined it as encompassing an initial development area of about $100 \mathrm{~km}^{2}$, a medium-term development area of about $200 \mathrm{~km}^{2}$, and a long-term control area of about $2000 \mathrm{~km}^{2}$. This new district has also been afforded national signifi- 
cance along the lines of the previously developed Shenzhen Special Economic Zone and Shanghai Pudong New District. The development of XND is a Millennium Plan, as well as a national event, recognized as a major historic strategic choice by the CPC Central Committee under the leadership of President Xi Jinping, and is of great strategic significance for the development of BTH and easing the non-capital functions of Beijing. At this critical moment, urgent planning and construction tasks necessitate an improved understanding of regional surface features within the proposed area of this new district to enable accurate estimations of future construction population and magnitude scale, as well as to propose land use, urban heat island, and other control measures to reveal future potential eco-environmental risks. Therefore, this study utilizes long-term data series of RS images, land use/cover change (LUCC), ecosystem service assessment, and high-precision urban land use information to synthetically analyze the ecosystem status of the counties of Xiongxian, Rongcheng, and Anxin ('Xiong'an three counties') in Hebei Province. We also proposed an ecological management and control strategy for this development and submitted 'Suggestions on Strengthening Regional Ecological Control in Construction of Hebei Xiong'an New District by Chinese Academy of Sciences Experts' to the CPC Central Committee on April 8th, 2017. Encompassing two aspects, the regional background of the BTH urban agglomeration and planning area coverage, this paper discusses the current urban agglomeration and impervious surface situation within the BTH area in the early 21 st century in the context of the overall development situation of this area, specifically the planned XND. We also present a scientific forecast of the ecological risks caused by the construction of XND in this study. This work is therefore an important scientific reference for the coordinated development of BTH and the construction of XND.

\section{Study area and data source}

\subsection{Study area}

The BTH urban agglomeration is the third largest in China after the Yangtze River Delta and the Pearl River Delta. This urban agglomeration is also the center of national political, cultural, and international exchange as well as scientific innovation, and encompasses a total land area of $216,300 \mathrm{~km}^{2}$, including 13 cities with a permenant population of 111 million and GDP of 6667.45 billion yuan. Subsequent to the process of reform and opening up, both economy and society have developed rapidly in China, leading to imbalances in the development of urban systems and causing major impacts on regional eco-environments. At the end of April 2015 and 2017, the CPC Central Committee and the State Council enacted the 'Beijing-Tianjin-Hebei Cooperation and Development Strategy' and made the decision to build 'Xiong'an New District' in order to promote the major national strategy for BTH. The aims of these developments were to ease the non-capital core functions of Beijing, adjust and optimize the urban spatial structure of the region, and to promote coordinated development of the regional eco-environment and socio-economy.

The planned XND covers Xiong'an three counties as well as surrounding areas within the city of Baoding in Hebei Province. These areas together comprise an equilateral triangle along with the cities of Beijing and Tianjin, encompassing a distance of about $110 \mathrm{~km}$. The total administrative area of Xiong'an three counties is about $1557 \mathrm{~km}^{2}$; the topography of 
this region is dominated by low altitude plains and depressions, while elevations range between $0 \mathrm{~m}$ and $44 \mathrm{~m}$ (average: $3.97 \mathrm{~m}$ ). Almost $70 \%$ of our study area, however, falls within an elevation range between $0 \mathrm{~m}$ and $5 \mathrm{~m}$, while $25 \%$ falls within a range between $5 \mathrm{~m}$ and 10 $\mathrm{m}$. At the beginning of 2015, the total population of Xiong'an three counties was 1.13 million, of which the agricultural population comprised $64 \%$ of the total, or 0.722 million. The non-agricultural population was 0.41 million, or $36 \%$ of the total. The gross domestic product of Xiong'an three counties is 21.106 billion yuan, with primary, secondary, and tertiary industries accounting for 2.869 billion yuan, 13.375 billion yuan, and 4.862 billion yuan, respectively (Table 1).

Table 1 Area, population, and economic statistics of administrative division of Xiong'an three counties in 2015

\begin{tabular}{|c|c|c|c|c|c|c|c|c|}
\hline \multirow[b]{2}{*}{ Name } & \multirow{2}{*}{$\begin{array}{l}\text { Area } \\
\left(\mathrm{km}^{2}\right)\end{array}$} & \multicolumn{3}{|c|}{ Population $(10,000)$} & \multicolumn{4}{|c|}{ Economic status (billion yuan) } \\
\hline & & Total & $\begin{array}{l}\text { Agri- } \\
\text { cultural }\end{array}$ & $\begin{array}{l}\text { Non-agr } \\
\text { icultural }\end{array}$ & GDP & $\begin{array}{l}\text { Primary } \\
\text { industry }\end{array}$ & $\begin{array}{c}\text { Secondary } \\
\text { industry }\end{array}$ & $\begin{array}{l}\text { Tertiary } \\
\text { industry }\end{array}$ \\
\hline Rongcheng & 314 & 27.31 & 13.73 & 13.58 & 5.775 & 0.971 & 3.415 & 1.389 \\
\hline Anxin & 729 & 46.30 & 32.35 & 13.95 & 6.256 & 0.885 & 3.604 & 1.767 \\
\hline Xiongxian & 514 & 39.41 & 26.12 & 13.29 & 9.075 & 1.013 & 6.356 & 1.706 \\
\hline Total & 1557 & 113.02 & 72.20 & 40.82 & 21.106 & 2.869 & 13.375 & 4.862 \\
\hline
\end{tabular}

Data extracted from the China County Statistical Yearbook, 2015.

\subsection{Data sources}

The main data sources used in this study include data on LUCC change, ecosystem macrostructure, digital terrain and geomorphology, and vegetation net primary productivity, as well as soil erosion RS data. We also downloaded Normalized Difference Vegetation Index (NDVI) data published by the National Aeronautics and Space Administration (https://ladsweb.modaps.eosdis.nasa.gov/archive/allData/6/MOD13Q1/), night light data released by the US National Oceanic and Atmospheric Administration (https://ngdc. noaa.gov/eog/download.html), high-resolution RS images from Google Earth, sub-basin boundary data from the United States Geological Survey and the Earth Resources Observation and Science Center (http://eros.usgs.gov/Find_Data/Products_and_Data_Available/gtopo30/hydro/asia), and data on Chinese administrative divisions from the National Geographic Information Center (http://ngcc.sbsm.gov.cn/), as well as other socio-economic and statistical information.

\subsection{Extracting land cover information from the urban agglomeration}

We extracted information about urban land use and ecosystem structure from the 2000, 2005, 2010, and 2015 National Land Use Datasets of China. These datasets are based on Landsat ETM/TM/OLI, HJ-1A, ZY-3 and other satellite images and rely on a unified standard artificial digital interpretation that comprises six classes (i.e., cropland, forest land, grassland, water, urban and rural construction land, and unused land) as well as 25 sub-classes. The average classification accuracy of these datasets is greater than $90 \%$, meeting the requirements of 1:100,000 scale mapping (Liu et al., 2002, 2010; Kuang et al., 2016b).

We extracted urban impervious surface distributional information every five years between 2000 and 2015 from a number of data sources including the NDVI and DMSP/OLS 
images, using urban construction land as a spatial mask. This approach is based on the work of Lu et al. (2008) who proposed the use of the impervious surface index of residential area and Kuang et al. (2013) who later modified this by applying regression correction parameters. We extracted urban impervious surface distribution information based on this modified index (Kuang et al., 2013) by establishing an impervious surface regression model at the regional scale (Figure 1a). We then calculated correlation coefficients and root mean square (RMS) error using the impervious surface distribution in 2015 as an example, and evaluated the accuracy of this approach using Google Earth high-resolution images and random sampling (Kuang et al., 2011, 2013, 2016a). The results of this method yielded a correlation coefficient of 0.78 and a RMS error of 0.17 , both of which satisfy the requirements of regional scale mapping.

\subsection{Ecological RS parameter acquisition and methods to evaluate ecosystem services}

The ecological RS parameter data used in this study includes vegetation cover, farmland productivity, and soil erosion. Vegetation cover was evaluated using the $250 \mathrm{~m}$ MODIS NDVI, while the NDVI maximum was obtained from preprocessed RS images. Farmland productivity data was expressed as net primary productivity (NPP) generated by the light energy utilization model satellite-based Vegetation Photosynthesis Model (VPM) based on MODIS RS and meteorological data (Xiao et al., 2004; Yan et al., 2007; Guo et al., 2015), while soil erosion data was obtained using the all-digital human-computer interaction analysis method founded on Landsat and other relevant auxiliary information, including digital elevation, soil type, vegetation coverage, and surface composition (Zhang et al., 2014).

Previous work has shown that there is a significant correlation between the area of impervious surface within a watershed and potential ecosystem health; thus, an increase in impervious surface area can seriously affect riverine ecosystems (Klein, 1979; Griffin et al., 1980; Schueler, 1987; Schueler, 1994; Elvidge et al., 2007; Peng et al., 2015). Because of this effect, we utilized the impact of urbanization on aquatic ecosystems as an indicator in this study; Bierwagen et al. (2010) found that when the proportion of impervious surface area (ISA) in a basin is less than $1 \%$, it will have no effect on an aquatic ecosystem. In contrast, when this proportion is between $1 \%$ and $5 \%$, there will be a slight effect on the aquatic ecosystem, but when the proportion is between $5 \%$ and $10 \%$, there will be moderate impact. Serious impacts will be observed in aquatic ecosystems when the ISA of a basin is between $10 \%$ and $25 \%$, and these effects will be severe when the proportion is larger than $25 \%$. We therefore applied a sub-basin impervious surface index model in this study to calculate this proportion within the sub-basin, using these threshold levels to assess potential impacts on riverine ecosystems. We used the formulae described by Kuang et al. (2011, 2013, 2016a).

\section{Results and analysis}

\subsection{Underlying characteristics of the BTH urban agglomeration}

As discussed, we evaluated spatiotemporal changes in urban expansion within the BTH urban agglomeration between 2000 and 2015. We also quantified dynamic changes and the environmental impacts of urban ISA changes within the study area. 


\subsubsection{Dynamic characteristics of urban expansion}

Dynamic changes in urban land use are illustrated in Figure 1, based on interpretation of LUCC data for the BTH urban agglomeration between 2000 and 2015. The data presented in Figure 1a reveal that the expansion of urbanization within the BTH urban agglomeration was significant at the start of the 21 st century, especially in Beijing and Tianjin, and that built-up land within these cities exhibited a sprawling expansion mode. Results reveal a $4,500.44 \mathrm{~km}^{2}$ increase in the area of urban land since 2000 , an average annual rate of increase of $300.03 \mathrm{~km}^{2} /$ year, up to about 1.27 times the total area of 2000 .

Results show significant differences in the expansion area of cities depending on stage. Expansion in urban land has mostly occurred within the six cities of Beijing, Tianjin, Shijiazhuang, Tangshan, Handan, and Langfang; taken together, these cities account for $71.76 \%$ of the total expansion area across the entire region. The cities of Beijing and Tianjin experienced the largest increases in urban expansion; the total expansion area of Beijing was $1004.78 \mathrm{~km}^{2}$, corresponding to a rate of $66.99 \mathrm{~km}^{2} /$ year, while the total expansion area of Tianjin was $682.945 \mathrm{~km}^{2}$, corresponding to a rate of $45.53 \mathrm{~km}^{2} /$ year. A large growth in urban land area has also been seen in Hebei Province and in the cities of Handan, Shijiazhuang, Tangshan, and Langfang, corresponding to a growth area of more than $300 \mathrm{~km}^{2}$ (Figure $1 \mathrm{~b}$ ).
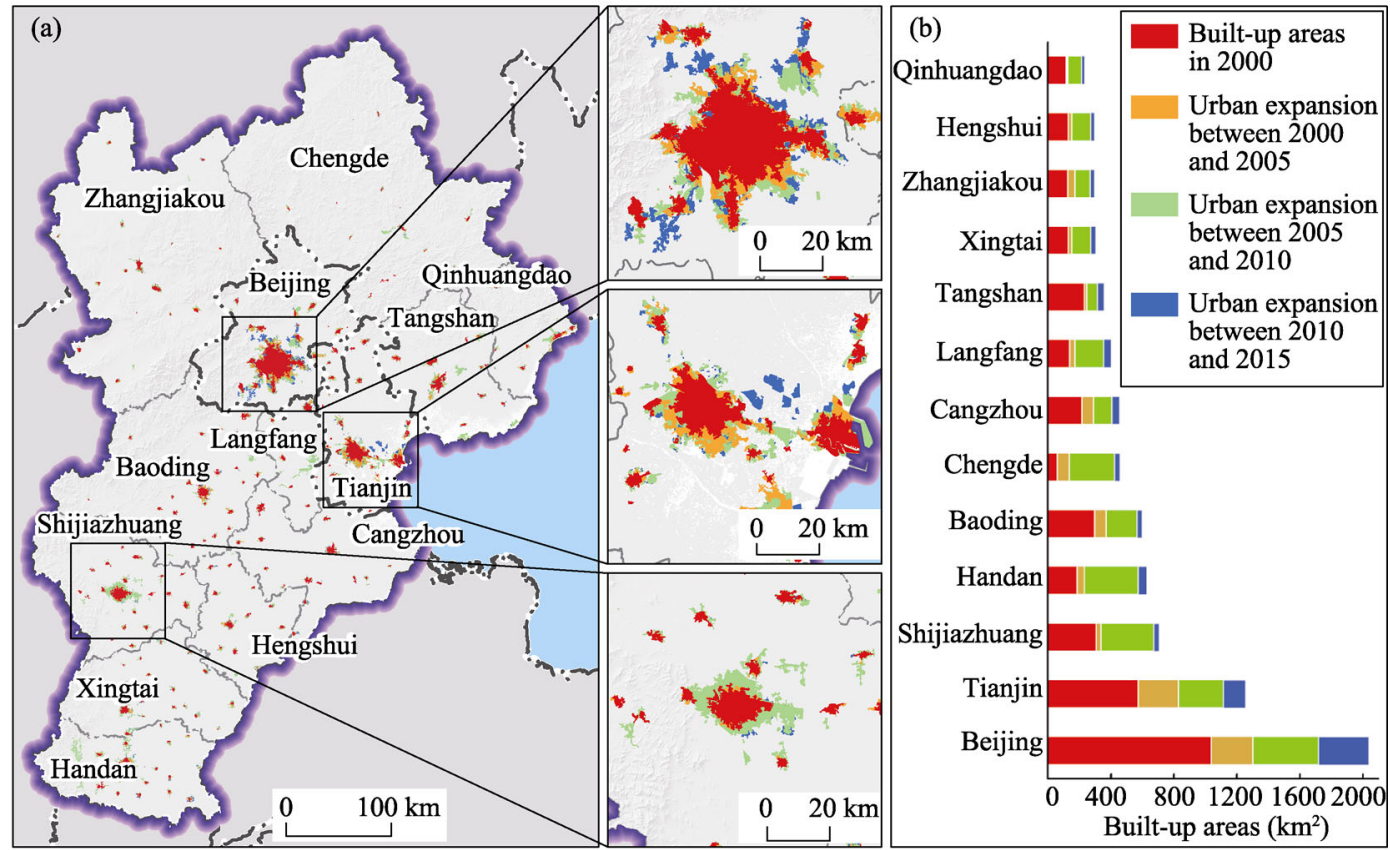

Figure 1 Dynamic changes in the expansion of built-up areas within the BTH urban agglomeration between 2000 and 2015

\subsubsection{Spatiotemporal patterns of urban impervious surface}

There has been continuous growth in ISA within the BTH urban agglomeration (Figure 2a) since the beginning of the 21 st century because of the expansion of urban construction land. Statistics show that the urban ISA of this region has increased by $3491.73 \mathrm{~km}^{2}$ over the last 15 years, 1.43 times the total area in 2000, and an average annual expansion rate of 232.78 $\mathrm{km}^{2} /$ year. The largest contributions to this growth were in Beijing and Tianjin, where total 
areas increased by $691.38 \mathrm{~km}^{2}$ and $581.45 \mathrm{~km}^{2}$, respectively, encompassing more than $36.45 \%$ of the regional total growth area. Similarly, the total ISA increased by more than 300 $\mathrm{km}^{2}$ in Tangshan, Handan, and Shijiazhuang; the growth of these three accounted for $27.83 \%$ of the regional total growth area. Areas in Langfang, Baoding, and Xingtai also increased by relatively large amounts, while the area of Chengde increased the least, by just $91.01 \mathrm{~km}^{2}$. The city of Beijing had the largest ISA within the region by 2015 , almost $1500 \mathrm{~km}^{2}$, followed by Tianjin, which experienced an increase of more than $1000 \mathrm{~km}^{2}$. Shijiazhuang, Tangshan, Handan, and Baoding all experienced increases of about $500 \mathrm{~km}^{2}$.
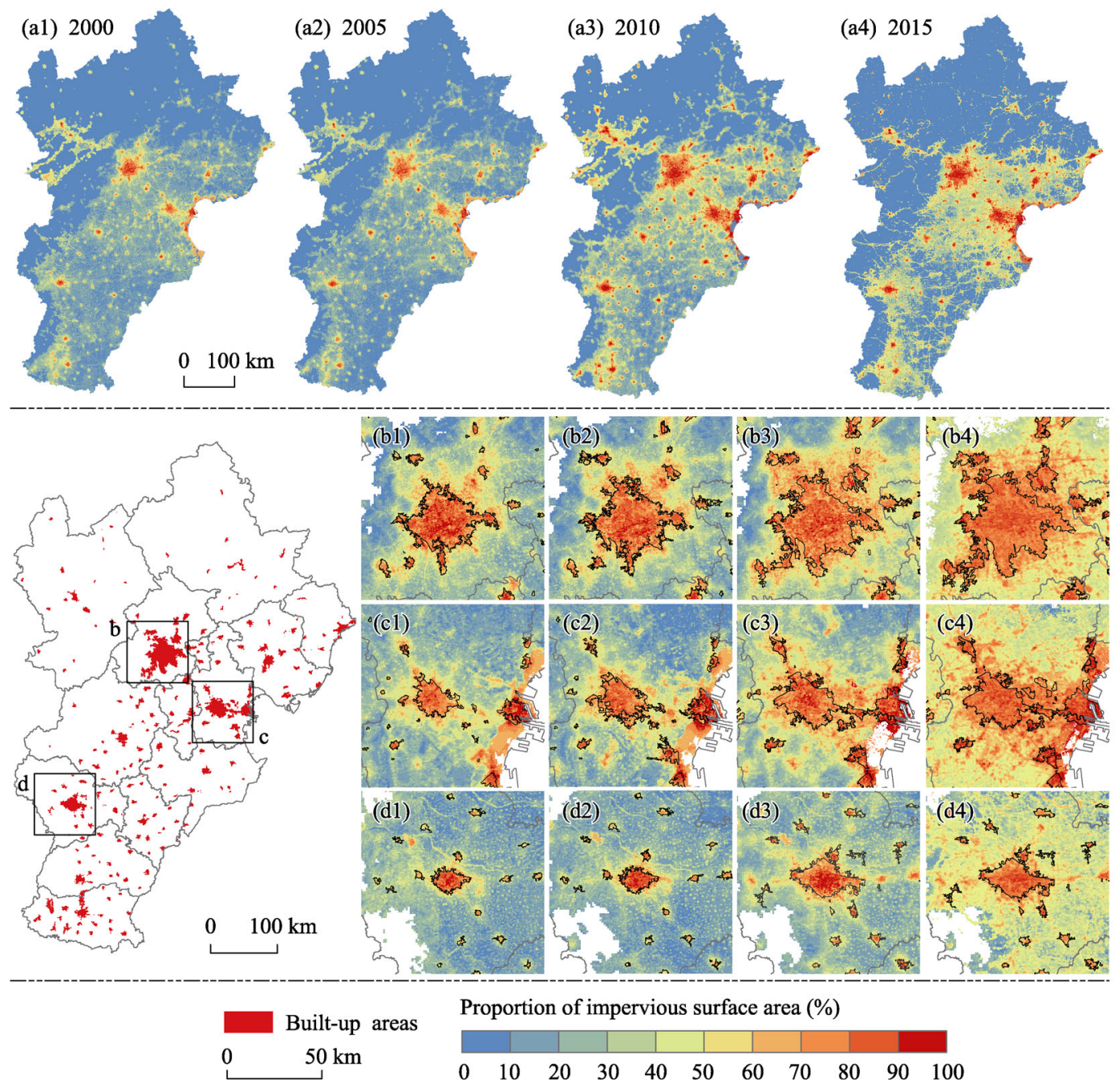

Figure 2 Maps showing the distribution of ISA within the BTH urban agglomeration and typical cities

Consistent with the overall trends in urban expansion, changes in ISA are characterized by sudden periods of rapid growth after slow growth before returning to their previous rates of change. Between 2000 and 2005, for example, the overall ISA of the region increased by $652.60 \mathrm{~km}^{2}$; within this, however, the cities of Beijing and Tianjin experienced substantial increases in ISAs, while other cities expanded more slowly. In contrast, between 2005 and 2010 , the ISAs of all the cities within this region increased rapidly at a rate of expansion 
3.05 times that of the earlier period. Between 2010 and 2015, this rate of growth suddenly reduced, however, to just $42.66 \%$ of the second period of analysis.

The data presented in Figures $2 \mathrm{~b}-2 \mathrm{~d}$ reveal that the area of built-up land within the three cities (Beijing, Tianjin, and Shijiazhuang) that comprise the BTH urban agglomeration has expanded significantly over the last 15 years and that the corresponding internal impervious surfaces have also gradually increased along with city expansion. Results show a more than $60 \%$ ISA proportion within each of the three cities, while growth of this type outside urban areas mainly includes increases in medium and higher density impervious surfaces radiating to surround urban, rural and suburban areas. These changes have resulted in the continuous layout and expansion of impervious surfaces within cities and surrounding areas.

We calculated the water-impermeable surface area proportion for each sub-basin in 2015 based on the boundaries of 92 regional sub-basins, and generated an ecological health impact rating for the water in each case. These results show that more than $60 \%$ of sub-basins within the study area were affected to different degrees by impervious surfaces; most of these sub-basins are located in the southeastern part of the study area and $78.15 \%$ of them were either affected seriously or severely, encompassing more than $57 \%$ of the total area (Figure 3 and Table 2). Seriously and severely affected sub-basin areas account for $21.12 \%$ of the total area, especially within Beijing and Tianjin, while the Bohai Bay region alongside sub-basins in Baoding, Shijiazhuang, and Handan have all been severely affected by impervious surfaces. In contrast, moderately affected sub-basins are predominantly and relatively continuously distributed in the southwestern part of the severely affected sub-basins, while northern, central, and southern parts of the sub-basins were least affected.

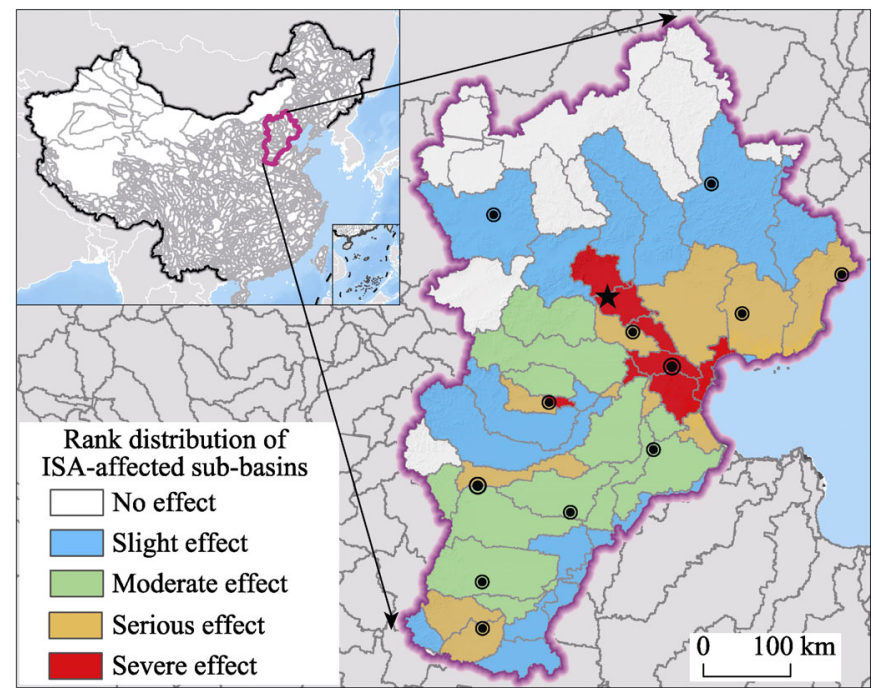

Figure 3 Map showing the ranked distribution of ISA affected sub-basins

Table 2 Statistics of ranked distribution of ISA affected sub-bains

\begin{tabular}{cccccc}
\hline \multirow{2}{*}{ Level } & $\begin{array}{c}\text { Proportion } \\
(\%)\end{array}$ & Number & Proportion $(\%)$ & Area $\left(\mathrm{km}^{2}\right)$ & Area proportion $(\%)$ \\
\cline { 3 - 6 } & $0-1.0$ & 36 & 39.13 & $47,049.57$ & 21.85 \\
No effect & $1-5$ & 16 & 17.39 & $71,577.27$ & 33.25 \\
Slight effect & $5-10$ & 14 & 15.22 & $51,203.34$ & 23.78 \\
Moderate effect & $10-25$ & 12 & 13.04 & $34,548.59$ & 16.05 \\
Serious effect & $25-100$ & 14 & 15.22 & $10,920.65$ & 5.07 \\
Severe effect & & 92 & 100.00 & $215,299.4$ & 100.00 \\
\hline Total & & & & &
\end{tabular}




\subsection{Status of ecological system and spatial governing strategies of Xiong'an three counties}

3.2.1 The ecological system structure of Xiong'an three counties

RS monitoring of ecological macrostructural changes between 2000 and 2015 revealed relatively large differences in farmland, townships, rural settlements, and water between Xiong'an three counties by the end of 2015 (Figure 4). Farmland ecosystems comprised the largest area $\left(697.79 \mathrm{~km}^{2}\right)$ within this region, encompassing $69 \%$ of the total area and mainly including dry farmland; just $51.56 \mathrm{~km}^{2}$ of paddy fields occur in Anxin County. The next most dominant LUCC types are urban and rural settlements $\left(303.39 \mathrm{~km}^{2}\right)$ which account for $19.49 \%$ of the region, especially townships and rural settlements, which comprise more than $80 \%$ of the urban and rural settlement area. Waters and wetland areas are ranked in third place, encompassing an area of $175.08 \mathrm{~km}^{2}$ and accounting for $11 \%$ of the region, most notably the freshwater Baiyangdian Lake (Table 3).

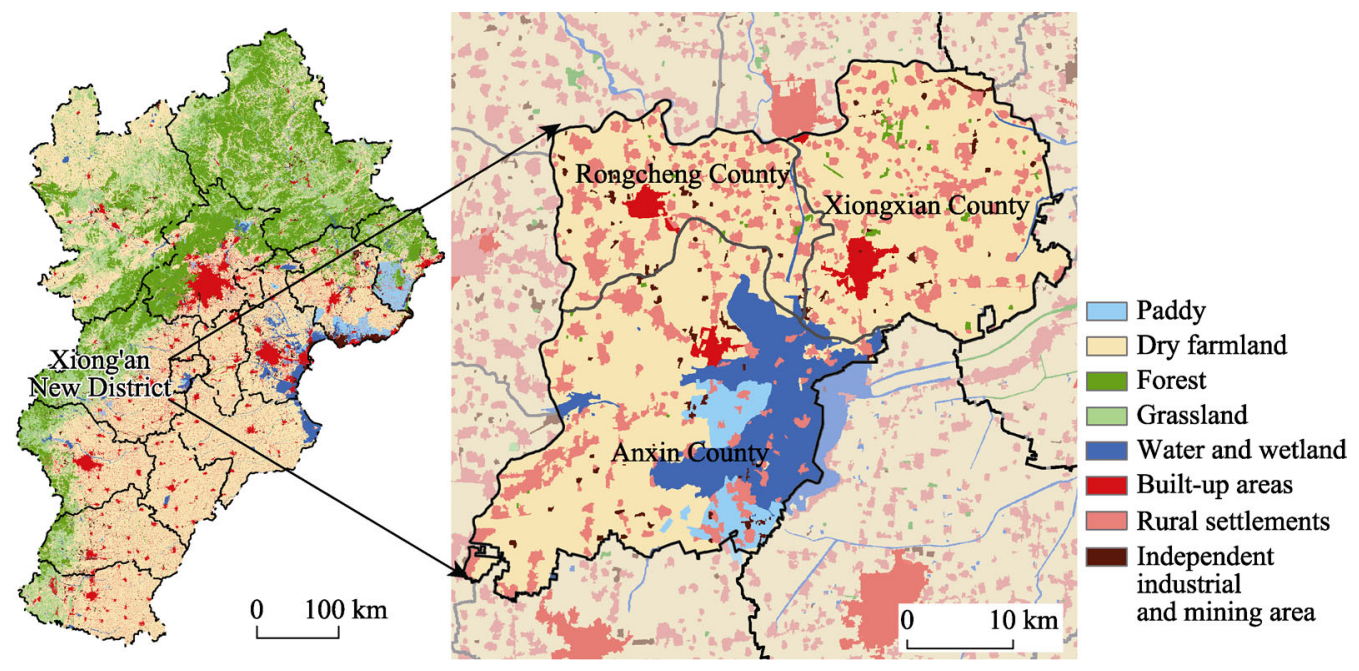

Figure 4 Maps showing the distribution of ecosystem types in Xiong'an three counties in 2015

Table 3 Area statistics of ecosystem classification of the Xiong'an three counties in $2015\left(\mathrm{~km}^{2}\right)$

\begin{tabular}{|c|c|c|c|c|c|c|c|}
\hline \multirow[b]{2}{*}{ Name } & \multicolumn{2}{|c|}{ Cropland } & \multirow[b]{2}{*}{ Forest } & \multirow{2}{*}{$\begin{array}{c}\text { Water and } \\
\text { wetland }\end{array}$} & \multicolumn{3}{|c|}{ Urban and rural settlements } \\
\hline & Paddy & $\begin{array}{c}\text { Dry } \\
\text { farmland }\end{array}$ & & & $\begin{array}{l}\text { Built- } \\
\text { up area }\end{array}$ & $\begin{array}{c}\text { Township and } \\
\text { rural settlements }\end{array}$ & $\begin{array}{l}\text { Independent industrial } \\
\text { and mining land }\end{array}$ \\
\hline Rongcheng & 0.00 & 224.72 & 1.59 & 5.70 & 9.22 & 67.29 & 5.22 \\
\hline Anxin & 51.56 & 391.61 & 1.02 & 163.90 & 7.56 & 99.79 & 10.55 \\
\hline Xiongxian & 0.00 & 399.90 & 6.51 & 5.48 & 17.58 & 79.74 & 6.42 \\
\hline Total & 51.56 & 1016.23 & 9.12 & 175.08 & 34.37 & 246.82 & 22.20 \\
\hline
\end{tabular}

Data show that urban and rural settlement areas have expanded significantly over the last 15 years within the three counties studied in this paper. The total area of expansion was $113.89 \mathrm{~km}^{2}$, of which built-up areas, townships and rural settlements, as well as independent industrial and mining land use expanded by $15.11 \mathrm{~km}^{2}, 82.99 \mathrm{~km}^{2}$, and $15.79 \mathrm{~km}^{2}$, respectively. At the same time, areas of cultivated land, water and wetlands within Xiong'an three counties decreased by $65.90 \mathrm{~km}^{2}$ and $96.80 \mathrm{~km}^{2}$, respectively. 
The proportions of non-agricultural population (36\%) as well as built-up areas $\left(34.37 \mathrm{~km}^{2}\right)$ within Xiong'an three counties in 2015 confirm that the level of urbanization within this region is relatively low. Data further demonstrate that the ISA of this region in 2015 was $110.45 \mathrm{~km}^{2}$, encompassing $36 \%$ of the urban and rural settlement area of Xiong'an three counties. The ISA contained within these three counties is $23.98 \mathrm{~km}^{2}$, corresponding to an average ratio of $70 \%$. Thus, because the area of urban land is small, no obvious heat island is evident within this region.

\subsubsection{Ecosystem services in Xiong'an three counties}

Utilizing RS data products in combination with model retrieval results for the period between 2000 and 2015, we evaluated the key ecosystem factors within Xiong'an three counties, including vegetation cover status, farmland production capacity, and soil erosion. Results show that ecosystem services remain in good condition within this region, including vegetation coverage, farmland production capacity, and soil conservation. However, due to enhanced disturbance, the vegetation cover within Xiong'an three counties has been slightly degraded over the last 15 years, although the NDVI was stable at 0.79 by 2015 (Figure 5a). This ecosystem type encompasses $76.4 \%$ of the total farmland area, is high quality, and generates significant yields (Figure $5 \mathrm{~b}$ ). Indeed, because of enhanced vegetation coverage and the superiority of farmland ecosystems in this area, soil erosion has been effectively mitigated; this kind of erosion within this region is dominated by slight water and wind erosion, comprising the weakest level of Chinese soil erosion.
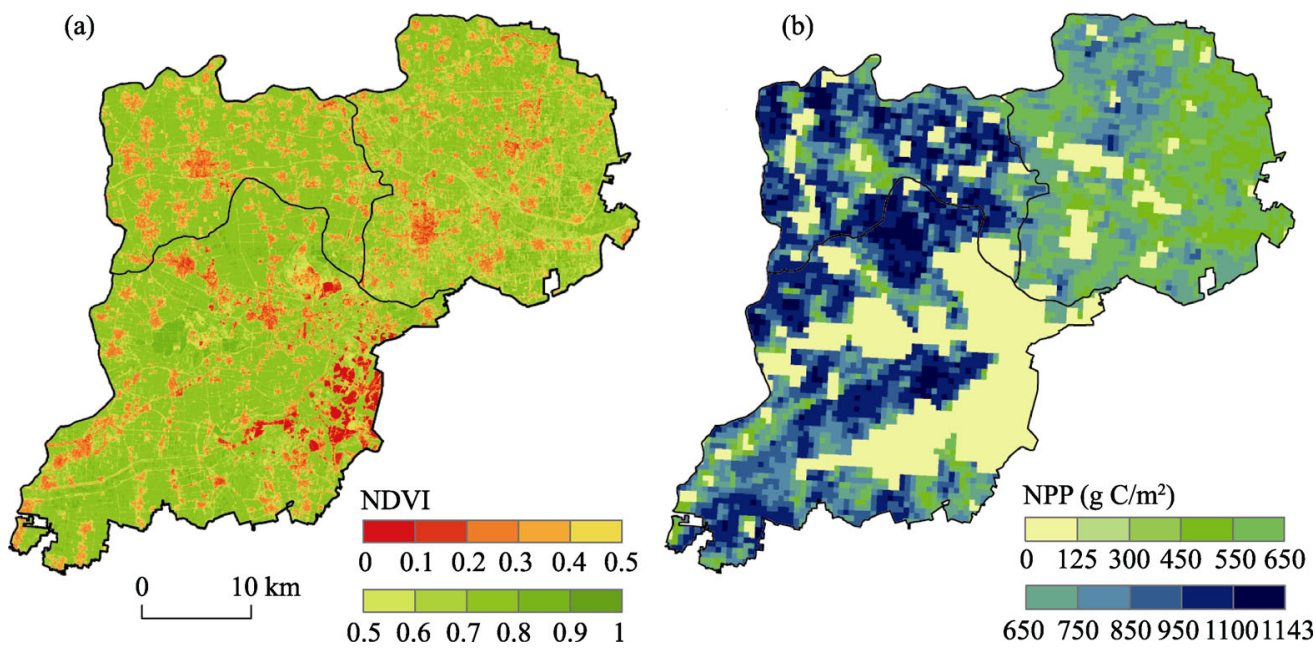

Figure 5 Maps showing the NDVI and NPP status of Xiong'an three counties in 2015

\subsection{Potential impacts of future ecological construction}

Comprehensive analysis and evaluation of potential eco-environmental impacts during different developmental stages has demonstrated that Xiong'an three counties is characterized by excellent ecological conditions as well as strong resources and environmental carrying capacities. This area is a low-lying plain as the average elevation of the three counties is just $3.97 \mathrm{~m}$ and $70 \%$ of the region has topography between $0 \mathrm{~m}$ and $5 \mathrm{~m}$ above sea level. In terms of ecosystem types, as about $80 \mathrm{~km}^{2}$ of cultivated land is present in addition to Bai- 
yangdian Lake, this region lacks large ecological patches such as forests or ecological source protection in terms of a wider range of ecological sources as urban footprints. It is therefore clear that the future planned construction of XND will need to focus on accommodating the demographic and industrial targets of easing the non-capital fuctions of Beijing, in particular controlling population growth and industrial magnitude at moderate levels in order to create an ecological and healthy city with a population of five million or less. In light of the factors discussed above, potential eco-environmental impacts on the construction of XND as well as proposed control measures are presented in Table 4.

Table 4 Potential eco-environmental impacts on the construction of XND and proposed control measures

\begin{tabular}{|c|c|c|c|c|}
\hline \multirow{2}{*}{$\begin{array}{l}\text { Expected impact and } \\
\text { regulation index }\end{array}$} & \multirow{2}{*}{$\frac{\text { Initial stage }}{\text { Expected by } 2020}$} & \multicolumn{2}{|c|}{ Medium-term } & \multirow{2}{*}{$\frac{\text { Long-term }}{\text { Expected by } 2050}$} \\
\hline & & Expected by 2025 & Expected by 2030 & \\
\hline Population size & $\begin{array}{l}\text { Between half a } \\
\text { million and one } \\
\text { million people }\end{array}$ & $\begin{array}{l}\text { Between one mil- } \\
\text { lion and two mil- } \\
\text { lion people }\end{array}$ & $\begin{array}{l}\text { Between two million } \\
\text { and five million people }\end{array}$ & $\begin{array}{l}\text { Greater than five } \\
\text { million people }\end{array}$ \\
\hline Built-up area & $\begin{array}{l}\text { Between } 60 \mathrm{~km}^{2} \text { and } \\
120 \mathrm{~km}^{2}\end{array}$ & $\begin{array}{l}\text { Between } 120 \mathrm{~km}^{2} \\
\text { and } 240 \mathrm{~km}^{2}\end{array}$ & $\begin{array}{l}\text { Between } 240 \mathrm{~km}^{2} \text { and } \\
600 \mathrm{~km}^{2}\end{array}$ & $\begin{array}{l}\text { Greater than } 600 \\
\mathrm{~km}^{2}\end{array}$ \\
\hline $\begin{array}{l}\text { Urban land use, } \\
\text { industrial regulation, } \\
\text { and control model }\end{array}$ & \multicolumn{2}{|c|}{$\begin{array}{l}\text { Ease Beijing city non-capital functions via } \\
\text { moderate control }\end{array}$} & \multirow{2}{*}{\multicolumn{2}{|c|}{$\begin{array}{l}\text { Strengthen the construction of the ecological } \\
\text { zone in the fringe area, and strictly control } \\
\text { continuous agglomerated sprawl growth } \\
\text { Control the ratio of ISAs to between } 50 \% \text { and } \\
60 \% \text {, and maintain the urban greening rate at a } \\
\text { level higher than } 40 \%\end{array}$}} \\
\hline $\begin{array}{l}\text { Impervious surface } \\
\text { control in built-up } \\
\text { areas }\end{array}$ & \multicolumn{2}{|c|}{ Control the ratio of ISAs to less than $60 \%$} & & \\
\hline Land use & \multicolumn{2}{|c|}{$\begin{array}{l}\text { Predominantly include cultivated land and } \\
\text { township rural residential areas. Build an } \\
\text { ecological protection zone between urban } \\
\text { areas and Baiyangdian Lake }\end{array}$} & \multicolumn{2}{|c|}{$\begin{array}{l}\text { Strengthen the control of green areas and an } \\
\text { ecological corridor between the cities of } \\
\text { Baoding, Beijing, and Tianjin to mitigate } \\
\text { continuous development along the traffic axis }\end{array}$} \\
\hline Urban heat island & \multicolumn{2}{|c|}{$\begin{array}{l}\text { Although the space occupied by urban heat } \\
\text { island will expand, this can be controlled } \\
\text { via urban ecological structures to a varia- } \\
\text { tion of } 1^{\circ} \mathrm{C}\end{array}$} & \multicolumn{2}{|c|}{$\begin{array}{l}\text { The space occupied by urban heat island will } \\
\text { continue to expand, but via scientific planning } \\
\text { this can be limited to variation between } 1^{\circ} \mathrm{C} \\
\text { and } 1.5^{\circ} \mathrm{C}\end{array}$} \\
\hline $\begin{array}{l}\text { Potential ecological } \\
\text { impacts and pro- } \\
\text { posed control strate- } \\
\text { gies }\end{array}$ & \multicolumn{2}{|c|}{$\begin{array}{l}\text { This region is low-lying and vulnerable to } \\
\text { storm impacts. Construction, population, } \\
\text { industry, and other urban agglomera- } \\
\text { tion-related factors will reduce ecosystem } \\
\text { water conservation and other service func- } \\
\text { tions }\end{array}$} & \multicolumn{2}{|c|}{$\begin{array}{l}\text { Expansion of impervious surfaces in urban areas, } \\
\text { coupled with the low-lying terrain, will in- } \\
\text { crease the risk of floods and other disasters. It will } \\
\text { therefore be necessary to consider ecological } \\
\text { protection and the development of a corridor } \\
\text { mosaic as part of eco-city planning and design }\end{array}$} \\
\hline $\begin{array}{l}\text { Potential environ- } \\
\text { mental impacts and } \\
\text { proposed control } \\
\text { strategies }\end{array}$ & \multicolumn{2}{|c|}{$\begin{array}{l}\text { Low-lying flat, high-rise buildings will } \\
\text { affect the diffusion capacity of the local } \\
\text { atmosphere, leading to increases in haze } \\
\text { and other pollution. In addition to being a } \\
\text { source of pollution, impervious surfaces } \\
\text { will enable other pollution sources and } \\
\text { damage the freshwater quality of Baiyang- } \\
\text { dian Lake. It will be necessary to strictly } \\
\text { develop systems to control industrial access } \\
\text { as well as high standards to deal with waste }\end{array}$} & \multicolumn{2}{|c|}{$\begin{array}{l}\text { The impervious surface proportion within the } \\
\text { sub-basin will rise to between } 15 \% \text { and } 25 \% \text {, } \\
\text { will significantly affect the health of the river } \\
\text { basin ecosystem, and will have a serious im- } \\
\text { pact on the water quality of Baiyangdian } \\
\text { Lake. It will be necessary to draw an itinerary } \\
\text { for urban green development, and guide con- } \\
\text { struction according to these guidelines }\end{array}$} \\
\hline
\end{tabular}

The results of this study lead us to recommend that, during the early planning stage, XND should be included as part of the national 'sponge city' construction pilot so that it can benefit from the international success of this low impact development model as a way to strengthen green infrastructure during city construction. At the same time, various other forms of planning should be implemented to consider the area as a whole and to build green areas and 
areas and ecological corridors between this new district and the regional cities (i.e., Baoding, Beijing, and Tianjin) in order to prevent continuous urban fringe development and impervious surfaces along traffic corridors. We recommend that, in addition to considering green rate indicators, the overall proportion of impervious surface should not exceed $60 \%$, increasing to a maximum of $70 \%$ in the core area of this development.

International standards suggest that if the proportion of impervious surfaces within a city sub-basin exceeds $25 \%$, there will be serious impacts on the surface water environment and ecosystem health, even potentially causing the destruction of the whole system. The development of XND is expected to lead to hundreds of square kilometers of artificial construction, triggering a very substantial increase in the area of impervious surfaces (i.e., buildings, roads, and squares). In concert with adverse topographic conditions, this will lead to increased surface water from rain and is likely to make flooding more frequent. This region is also likely to face a number of additional issues including the development of high-intensity urban heat island and weakened atmospheric diffusion. Considering the level of these surfaces in a number of typical cities across China and the United States, it is clear that when the impervious surface covered proportion within a city exceeds $70 \%$ of ground area there will be a concomitant exponential rise in urban heat island. Similarly, when the proportion of impervious surfaces within a city sub-basin exceeds $25 \%$, indicators of river pollutants such as nitrogen and sulfur dioxide will increase significantly due to the effects of urban non-point source pollution (Kuang et al., 2011). It will therefore be necessary to prevent damage to the urban thermal environment as well as to mitigate adverse effects on the freshwater quality of Baiyangdian Lake that will result from large-scale continuous urban construction. It will also be important to comprehensively consider the effects of storm floods inside XND that might result from the presence of low-lying areas, poor wind diffusion caused by weak wind field intensity of prevailing wind, and the aggravation of urban heat island.

Finally, although XND includes Baiyangdian Lake, the largest expanse of freshwater on the North China Plain, this construction area is also located within the Daqinghezi watershed of the Haihe River Basin which generates total water resources of just only 246.21 million $\mathrm{m}^{3}$ (an average of $217 \mathrm{~m}^{3}$ per person). Data from the water sector shows that groundwater exploitation in Anxin, Xiongxian, and Rongcheng counties is currently mild, moderate, and seriously over-exploited, respectively, which translates to a marked lack of water and groundwater resources in Xiong'an three counties that support the development of XND. This new development therefore needs to be based on the concept of 'planning city according to water resource amount', taking full account of the carrying capacity status of water resources, as well as the 'sponge city' concept and the international 'low impact development' model. The construction of infrastructure, water supply and drainage within XND must therefore make full use of rainwater collection and recycling to improve the comprehensive utilization and ecological protection of these resources, including water ecology and environment.

\section{Discussion and conclusions}

This paper analyzes the natural and socio-economic development of the BTH urban ag- 
glomeration using the current development strategy as a basis. We conclude that the construction of XND is critical to organically mitigate the non-capital functions of Beijing, to promote regional socio-economic development, and to enhance the service functions of urban ecosystem. Based on the 'multi-scale nested adaptive cycle' and 'Resilience' theories proposed by Holling and Gunderson (2002), the dynamic evolution of urban ecosystems should include four stages of growth or exploitation, conservation or accumulation, collapse and release, and reorganization and renewal. According to these theories, the cities of Beijing, Tianjin, Shijiazhuang, and Baoding are all at different stages of development, while the current state of XND construction has also reached a level that is inevitable given the developmental evolution of urban agglomerations. Carpenter et al. (2001) also pointed out that a resilient urban system should include at least three characteristic attributes, i.e., an ability to absorb external disturbances yet remain in the same state, an ability to self-organize, and some degree of system learning and adaptive capacity. As one key goal of the national 'Millennium Plan', the development of XND has great significance to the re-organization and updated development of urban ecosystems, as well as to improvements in their self-organization and adaptability.

Since the beginning of the 21 st century, the proportion of urban land and impervious surfaces within the BTH urban agglomeration has increased very rapidly. Data show that urban land area has increased by $4500.44 \mathrm{~km}^{2}$ since 2000 , while the area of impervious surfaces has increased by $3491.73 \mathrm{~km}^{2}$. The internal impervious surface ratio within $15 \%$ of sub-basins is greater than $25 \%$, leading to serious impacts on the health of aquatic ecosystems within watersheds. Thus, the nature of the overall underlying surface within the BTH urban agglomeration, especially impermeable areas, is a core issue that has led to ecological problems within the urban agglomeration. We would argue that insufficient attention has so far been paid to this problem. The XND construction site is located on a low-lying plain, 110 $\mathrm{km}$ from the cities of Beijing and Tianjin, and close to the freshwater Baiyangdian Lake. Although this location possesses certain resources and environmental advantages, considering topographic features, ecosystem types, urban rain, flood, and heat island regulations, as well as the necessity for clean urban air, construction must be characterized by the rational implementation of ecological controls and protection.

Utilizing geographical and ecological information obtained from high-resolution RS images and ecological models, this paper has reviewed the regional ecological characteristics, patterns, and service status of the construction of XND given the regional background of the BTH urban agglomeration and the area encompassed by this planned development. We also estimate the potential future ecological and environmental risks of this development and propose a series of ecological protection and control strategies for different developmental stages that we hope will be of significant value to the early planning and construction of XND.

\section{References}

Bierwagen B G, Theobald D T, Pyke C R et al., 2010. National housing and impervious surface scenarios for integrated climate impact assessments. PNAS, 107(49): 20887-20892.

Carpenter S, Walker B, Anderies J M, et al. 2001. From metaphor to measurement: Resilience of what to what? 
Ecosystems, 4(8): 765-781.

Chen J Q, Yan H M, Wang S Q et al., 2014. Estimation of gross primary productivity in Chinese terrestrial ecosystems by using VPM Model. Quaternary Sciences, 34(4): 732-742.

Elvidge C D, Tuttle B T, Sutton P C et al., 2007. Global distribution and density of constructed impervious surfaces. Sensor, 7(9): 1962-1979.

Fang Chuanglin, 2014. Progress and the future direction of research into urban agglomeration in China. Acta Geographica Sinica, 69(8): 1130-1144. (in Chinese)

Fang Chuanglin, Zhou Chenghu, Gu Chaolin et al., 2016. Theoretical analysis of interactive coupled effects between urbanization and eco-environment in mega-urban agglomerations. Acta Geographica Sinica, 71(4): 531-550. (in Chinese)

Griffin D M, Grizzard T J, Randall C W et al., 1980. Analysis of non-point pollution export from small catchments. Journal (Water Pollution Control Federation), 52(4): 780-790.

Grimm N B, Faeth S H, Golubiewski N E et al., 2008. Global change and the ecology of cities. Science, 319(5864): 756-760.

Gu Chaolin, 2011. Study on urban agglomeration: Progress and prospects. Geographical Research, 16(4): 82-88. (in Chinese)

Guo Rongchao, Miao Changhong, Xia Baolin et al., 2010. Research on the model of optimization and reorganization of eco-spatial structure in urban agglomeration region and its application: A case study of the urban agglomeration in Central Plains Region. Progress in Geography, 29(3): 363-369. (in Chinese)

Guo W, Lu D S, Wu Y L et al., 2015. Mapping impervious surface distribution with integration of SNNP VIIRS-DNB and MODIS NDVI Data. Remote Sensing, 7(9): 12459-12477.

Holling C S, 1973. Resilience and stability of ecological systems. Annual Review of Ecology and Systematics, 4(1): 1-23.

Holling C S, Gunderson L H, 2002. Panarchy: Understanding Transformations in Systems of Humans and Nature. Resilience and Adaptive Cycles. Washington: Island Press, 25-62.

Jha A, Lamond J, Proverbs D et al., 2012. Cities and flooding: A guide to integrated urban flood risk management for the 21 st century. General Information, 52(5): 885-887.

Jones B, O’Neill B C, McDaniel L et al., 2015. Future population exposure to US heat extremes. Nature Climate Change, 5(7): 652-655.

Jones H P, Hole D G, Zavaleta E S, 2012. Harnessing nature to help people adapt to climate change. Nature Climate Change, 2(7): 504-509.

Kuang W H, Chen L J, Liu J Y et al., 2016a. Remote sensing-based artificial surface cover classification in Asia and spatial pattern analysis. Science China Earth Sciences, 59(9): 1720-1737.

Kuang W H, Chi W F, Lu D S et al., 2014. A comparative analysis of megacity expansions in China and the U.S.: Patterns, rates and driving forces. Landscape and Urban Planning, 132: 121-135.

Kuang W H, Dou Y Y, Zhang C et al., 2015a. Quantifying the heat flux regulation of metropolitan land use/land cover components by coupling remote sensing modeling with in situ measurement. Journal of Geophysical Research: Atmospheres, 120(1): 113-130.

Kuang Wenhui, Chi Wenfeng, Lu Dengsheng et al., 2015b. Remote Sensing Analysis and Ecological Control of Urban Surface Thermal Environment. Beijing: Science Press, 109. (in Chinese)

Kuang W H, Liu J Y, Dong J W et al., 2016b. The rapid and massive urban and industrial land expansions in China between 1990 and 2010: A CLUD-based analysis of their trajectories, patterns, and drivers. Landscape and Urban Planning, 145: 21-33.

Kuang Wenhui, Liu Jiyuan, Lu Dengsheng, 2011. Pattern of impervious surface change and its effect on water environment in the Beijing-Tianjin-Tangshan Metropolitan Area. Acta Geographica Sinica, 66(11): 1486-1496. (in Chinese)

Kuang W H, Liu J Y, Zhang Z X et al., 2013. Spatiotemporal dynamics of impervious surface areas across China during the early 21st century. Chinese Science Bulletin, 58(14): 1691-1701. 
Kuang W H, Yang T R, Liu A L et al., 2017. An ecocity model for regulating urban land cover structure and thermal environment: Taking Beijing as an example. Science China Earth Sciences, 60(6): 1098-1109.

Leichenko R., 2011 Climate change and urban resilience. Current Opinion in Environmental Sustainability, 3(3): $164-168$.

Lelieveld J, Evans J S, Fnais M et al., 2015. The contribution of outdoor air pollution sources to premature mortality on a global scale. Nature, 525(7569): 367-371.

Liu J Y, Liu M L, Zhuang D F et al., 2002. Study on spatial pattern of land-use change in China during 1995-2000. Science in China: Series D, 32(12): 1031-1040.

Liu J Y, Zhang Z X, Xu X L et al., 2010. Spatial patterns and driving forces of land use change in China during the early 21st century. Journal of Geographical Sciences, 20(4): 483-494.

Liu Zhenhuan, Wang Yanglin, Peng Jian, 2012. Quantifying spatiotemporal patterns dynamics of impervious surface in Shenzhen. Geographical Research, 31(8): 1535-1545. (in Chinese)

Lu Dadao, 2008. The Regional Developing strategy, tendency and the development of Jing-Jin-Ji. Social Science of Beijing, (6): 4-7. (in Chinese)

Lu D S, Tian H Q, Zhou G M et al., 2008. Regional mapping of human settlements in southeastern China with multi-sensor remotely sensed data. Remote Sensing of Environment, 112(9): 3668-3679.

Ma T, Zhou C H, Pei T et al., 2014. Responses of Suomi-NPP VIIRS-derived nighttime lights to socioeconomic activity in China's cities. Remote Sensing Letters, 5(2): 165-174.

Meerow S, Newell J P, Stults M, 2016. Defining urban resilience: A review. Landscape and Urban Planning, 147: $38-49$.

Ouyang Z Y, Zheng H, Xiao Y et al., 2016. Improvements in ecosystem services from investments in natural capital. Science, 352(6292): 1455-1459.

Peng J, Liu Y X, Shen H et al., 2016. Using impervious surfaces to detect urban expansion in Beijing of China in 2000s. Chinese Geographical Science, 26(2): 229-243.

Peng J, Liu Y X, Wu J S et al., 2015. Linking ecosystem services and landscape patterns to assess urban ecosystem health: A case study in Shenzhen City, China. Landscape and Urban Planning, 143: 56-68.

Pickett S T A, McGrath B, Cadenasso M L et al., 2014. Ecological resilience and resilient cities. Building Research \& Information, 42(2): 143-157.

Schueler T K, 1987. Controlling Urban Runoff: A Practical Manual for Planning and Designing Urban BMPs. Washington: MWCOG, 1-10.

Schueler T K, 1994. The importance of imperviousness. Watershed Protection Techniques, 1: 100-101.

Weng Q H, Lu D S, 2009. Landscape as a continuum: an examination of the urban landscape structures and dynamics of Indianapolis City, 1991-2000, by using satellite images. International Journal of Remote Sensing, 30(10): 2547-2577.

Wu J G, Jenerette G D, Buyantuyev A et al., 2011. Quantifying spatiotemporal patterns of urbanization: The case of the two fastest growing metropolitan regions in the United States. Ecological Complexity, 8(1): 1-8.

Xiao X M, Zhang Q Y, Braswell B et al., 2004. Modeling gross primary production of temperate deciduous broadleaf forest using satellite images and climate data. Remote Sensing of Environment, 91(2): 256-270.

Yan Huimin, Liu Jiyuan, Cao Mingkui, 2007. Spatial pattern and topographic control of China's agricultural productivity variability. Acta Geographica Sinica, 62(2): 171-180. (in Chinese)

Zhang Zengxiang, Zhao Xiaoli, Wang Xiao et al., 2014. Remote Sensing Monitoring of Soil Erosion in China. Beijing: Planet Map Press, 23-30. 